\section{Autodeterminação e Empreendedorismo com Suporte em Motivações: análise empírica com universitários do curso de administração}

\author{
Fabiana Pinto de Almeida Bizarria, Flávia Lorenne Sampaio Barbosa e \\ Antônia Márcia Rodrigues Sousa
}

\section{RESUMO}

A pesquisa investiga a influência da Motivação Acadêmica na Motivação Empreendedora, com base na relação das sete dimensões da Escala de Motivação Acadêmica (Desmotivação, Regulação Externa, Regulação Introjetada, Regulação Identificada, Motivação a Experimentar, a Realizar e a Saber) na Motivação Empreendedora. Utilizou-se de uma amostra de 245 universitários de administração, pertencentes a sete Instituições de Ensino Superior, em três cidades do Nordeste. As hipóteses foram aferidas por meio de um modelo estrutural, estimado pelo método Partial Least Squares Path Modeling (PLS-PM). Os resultados apontaram relações positivas entre Desmotivação Acadêmica, bem como as dimensões da Motivação Extrínseca (Regulação Externa e Regulação Introjetada), à Motivação Empreendedora. Acredita-se que o estudo potencialmente avance no sentido de considerar que o aprendizado não supre as reais expectativas e motivações dos acadêmicos para empreender. Para tanto, sugere-se que cursos e programas, que visem a formação empreendedora, conduzam seus objetivos de forma a moldar-se às motivações prévias dos alunos, a fim de obter maior eficácia pedagógica.

Palavras-chave: motivação acadêmica; motivação intrínseca; motivação extrínseca; teoria da autodeterminação; empreendedorismo.

Self-Determination and Entrepreneurship with Motivation Support: Empirical analysis with university students of the administration course

\section{ABSTRACT}

The research investigates the influence of Academic Motivation on Entrepreneurial Motivation, based on the relation of the seven dimensions of the Academic Motivation Scale (Demotivation, External Regulation, Introduced Regulation, Identified Regulation, Motivation to Experiment, to Realize and to Know) in Entrepreneurial Motivation. A sample of 245 university students from seven higher education institutions in three cities of the Northeast were used. The hypotheses were measured using a structural model, estimated by the Partial Least Squares Path Modeling (PLS-PM) method. The results pointed out the positive relationship between Academic Demotivation, as well as the dimensions of Extrinsic Motivation (External Regulation and Introduced Regulation), to Entrepreneurial Motivation. It is believed that the study potentially moves towards considering that learning does not provide real expectations and motivations for academics to undertake. The study suggests that courses and programs, aimed at entrepreneurship training, should lead to their objectives in order to shape students' previous motivations to achieve greater pedagogical effectiveness.

Keyword: academic motivation; intrinsic motivation; extrinsic motivation; theory of self-determination; entrepreneurship.
Recebido em: 19/02/2018 Revisado em: 08/03/2018 Aprovado em: 10/04/2018

Check for updates

Fabiana Pinto de Almeida Bizarria iD,

Universidade da Integração Internacional da Lusofonia AfroBrasileira, Brasil

Doutora em Administração,

Universidade de Fortaleza, Brasil

bianapsq@hotmail.com

Flávia Lorenne Sampaio Barbosa (iD,

Universidade Federal do Piaú, Brasil Doutoranda em Administração, Universidade de Fortaleza, Brasil

flsbarbosa@hotmail.com

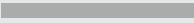

Antônia Márcia Rodrigues Sousa (iD),

Universidade Federal do Mato Grosso do Sul, Brasil

Doutora em Administração,

Universidade de Fortaleza, Brasil

pesquisadoramarciarodrigues@ gmail.com 
Introdução

Oestudo do empreendedorismo coloca-se em contínuo desenvolvimento, cuja relevância se deve à contribuição para o desenvolvimento econômico e social, com a criação e implementação de negócios em ambientes complexos e incertos, sendo apreciado como solução para o desemprego, pois é uma opção de carreira (Farhangmehr, Gonçalves,\& Sarmento, 2016; Morris, Kuratko \& Pryor, 2013; Morris, Shirokova, \& Tsukanova, 2017; Wang, Lin, Yeh, Li, \& Li, 2016).Nesse sentido, aconselha-se que a formação profissional na sociedade moderna favoreça que indivíduos possam ajustar-se a esse contexto de mudanças, com suporte à tomada de Decisões e consciência da importância da autonomia (Barros, 2015).

As Instituições de Ensino Superior [IES] possuem um fundamental papel no estímulo à autonomia, sendo esse aspecto central à ação empreendedora e, com isso, tem-se a ampliação da persistência, determinação e flexibilidade (Barros, 2015). Argumenta-se sobre a necessidade de "pensar fora da caixa", para fortalecer a ação autônoma, haja vista que se espera que os estudantes consigam responder às demandas do mundo do trabalho (Gibb, 2002). Dessa forma, quanto maior o estímulo a autonomia, maiores são as chances de que a criatividade seja exercitada (Gagné \& Deci, 2005).

Nessadireção, observa-seaexpansão daformaçãoemempreendedorismo na maioria dos países industrializados (Caray \& Matlay, 2007; Hytti, Stenholm, Heinonen, \& Seikkula-Leino, 2010), bem como a preocupação de governos no que tange aos programas de apoio ao empreendedorismo no âmbito universitário (Preedy \& Jones, 2015). Há, no entanto, resultados contraditórios quando se analisa a relação entre educação para o empreendedorismo e empreendedorismo (Colette, 2015; Joensuu-Salo, Varamäki, \& Viljamaa, 2015), embora estudos apontem que há influência dessa relação no número e na qualidade dos empreendedores (Matlay, 2008).

Constatam-se avanços em termo de matrizes curriculares, aproximando ensino e mercado, com ênfase no papel do empreendedorismo, com abordagens interdisciplinares. Contudo, evidencia-se o não abandono de métodos tradicionais de ensino e um baixo índice de graduados iniciando novos negócios (Morris, Shirokova, \& Tsukanova, 2017). No caso brasileiro, por exemplo, o curso de administração ainda dá ênfase a uma formação para a ocupação de empregos no Mercado de Trabalho (Lavieri, 2010).

Nessa perspectiva, a formação empreendedora pode revelar-se insuficiente para as necessidades econômicas e sociais dos países (Ferreira, Loiola, \& Gondim, 2016), bem como desenvolve-se em contexto universitário que restringe o desenvolvimento de comportamentos empresariais (Morris, Shirokova, \& Tsukanova, 2017), ao passo que não explora as expectativas/ motivação dos alunos anteriores à formação (Hytti, Stenholm, Heinonen, \& Seikkula-Leino , 2010). Dessa forma, Athayde (2009) e Wang., Lin, Yeh, Li \& Li (2016) ressaltam que a relação educação/empreendedorismo, ainda não foi respondida de forma abrangente, considerando necessárias as investigações sobre a disposição dos alunos ao empreendedorismo, assim como suas motivações ao se engajarem em novos empreendimentos. Farhangmehr, Gonçalves \& Sarmento (2016) apontam que a educação 
para o empreendedorismo não melhora a motivação dos estudantes universitários para se tornarem empreendedores.

Adicionalmente, os estudos de Hytti, Stenholm, Heinonen, \& Seikkula-Leino (2010) e Morris, Shirokova \& Tsukanova (2017) demostram que a análise das motivações dos estudantes para o estudo do empreendedorismo pode favorecer a eficácia pedagógica dos cursos, ao passo que acadêmicos que possuem diferentes níveis de motivação respondem de formas distintas ao programa. Hytti, Stenholm, Heinonen, \& Seikkula-Leino. (2010), por exemplo, identificam a relação entre a Motivação Intrínseca e a Motivação Extrínseca para apreender empreendedorismo e a Eficácia da Aprendizagem.

A relação negativa entre motivação intrínseca para aprender empreendedorismo e eficácia da aprendizagem é explicada como relacionada ao fato de que estudantes com altos níveis de autodeterminação (Motivação Intrínseca) possuem necessidades de aprendizagem não atendidas pelos programas do curso, fato corroborado pelo não aprimoramento das habilidades requeridas para criação de um negócio (Hytti, Stenholm, Heinonen, \& Seikkula-Leino 2010; Morris, Shirokova \& Tsukanova, 2017). A influência de níveis baixos de autodeterminação (Motivação Extrínseca) e eficácia da aprendizagem, por sua vez, converge com a ideia de que os alunos percebem o curso pelo seu valor instrumental (precisa ser concluído). Sendo assim, o objetivo é terminar a tarefa e obter o resulto que o levará ao título, à conclusão do curso (Hytti, Stenholm, Heinonen, \& Seikkula-Leino, 2010; Morris, Shirokova \& Tsukanova, 2017).

Nessa mesma linha, acadêmicos com altos níveis de desmotivação para geração de ideias de negócio podem buscar novas formas de obter conhecimento (mais rápidas, menos onerosas, mais virtualizadas, mais direcionadas). Esse fato é revelado pelo documentário Ivory Tower (Torre de Marfim) que estreou no Festival de Cinema de Sundance nos Estados Unidos, demonstrando a crise vivenciada pelo modelo Universitário Norte Americano, especificamente pelo nível de endividamento estudantil, estimado em US\$1 trilhão, em 2014.

O documentário apresenta um movimento, a exemplo do Learn Capital e Uncollege, de estímulo ao abandono da faculdade, inspirado por exemplos de Steve Jobs (Apple) que abandonou Reed College, 1973; Bill Gates (Microsoft) que abandonou Harvard, 1975; e Mark Zuckerberg (Facebook) que abandonou Harvard em 2004. Segundo o documentário, a cidade de São Francisco, onde se situa a Casa dos Hackers (reunião de ex-universitários com o objetivo de criar incubadoras educacionais), tem registrado o crescimento desse abandono, apoiado pela Fundação Thiel (criado por Peter Thiel, também fundador do Paypal), que inclusive financia alunos para que se dediquem ao empreendedorismo em vez de ir à faculdade.

Diante desse contexto, mesmo que uma Motivação Intrínseca (com maior nível de autonomia/autodeterminação) (Gagné \& Deci, 2005) implique em maior qualidade de aprendizagem (Niemiec \& Ryan, 2009), quando associada à motivação empreendedora, supõe-se que indivíduos tendem se engajar na formação pelo prazer que o novo conhecimento proporciona e não pelo desejo/necessidade de empreender (Deci \& Ryan, 2000, 2008). 
Assim, acredita-se que menores níveis de autodeterminação manifestados pela motivação acadêmica relacionem-se positivamente com as motivações empreendedoras, ao passo que os maiores níveis de autodeterminação se relacionem negativamente.

Dessa forma, com base no questionamento da Motivação Acadêmica sobre a Motivação Empreendedora, o estudo dá um novo direcionamento à relação educação/empreendedorismo, avigorando o contexto universitário e o lócus da pesquisa.

Mostrando um panorama atrativo e importante para a disseminação efetiva da educação para o empreendedorismo, relacionando programas que equacionem as diferentes expectativas e motivações dos acadêmicos (Hytti, Stenholm, Heinonen, \& Seikkula-Leino 2010; Morris, Shirokova \& Tsukanova, 2017).

\section{Teoria da Autodeterminação e Motivação} Acadêmica

A motivação humana surge como tema emergente na década de 1940, com Maslow (1943), Alderfer (1969), McClelland, Atkinson \& Lowell (1953), e avançou de uma concepção de necessidade (falta/carência), para teorias que dão maior suporte à ação. Mais recentemente, as teorias Sóciocognitivas (Bandura, 1999), Auto-regulação (Kanfer \& Heggestad, 1997) e Autodeterminação (Ryan \& Deci, 2000) têm apontado novas perspectivas ao estudo do tema.

No que diz respeito à Teoria da Autodeterminação [TAD], o estudo da motivação deriva da análise de suas dimensões (intrínseca e extrínseca), em diferentes níveis de intensidade e tipos motivacionais (Cokley, 2015; Gagné \& Deci, 2005). Nessa linha teórica, os fatores ambientais e condições sociais passaram a centralizar o debate, principalmente após constatações sobre a diminuição da motivação intrínseca quando há o acréscimo de recompensas à dimensão extrínseca (Deci \& Ryan, 2000; Lepper, Henderlong \& lyengar, 2005). A TAD possui amparo em abordagens interacionistas, socioculturais e assume que o homem possui capacidade de autorregulação. Este é o fator que impulsionaria o homem à busca de suas necessidades, como a de autonomia e bem-estar (Cokley, 2015; Deci \& Ryan, 2000).

A TAD (Figura 1) acomoda um processo contínuo entre desmotivação por um lado caracterizada pela ausência de autodeterminação e, por outro lado, a motivação intrínseca. Essa associação de construtos é caracterizada pela autodeterminação plena, quando a ação é desencadeada pela necessidade de regulação interna, alinhando Decisões aos interesses pessoais (Gagné \& Deci, 2005). 
Figura 1.0 contínuo da motivação na escala de motivação acadêmica

Fonte: Adaptada pelos autores (2017) a partir de Zhang, Li, Li, Li \& Zhang (2016).

A motivação intrínseca, associada à um maior nível de autodeterminação, corresponde à disposição que mobiliza o homem a agir de maneira que resulte em sensações agradáveis. Assim, as ações exploradas pelo sujeito possuem a finalidade de uma satisfação espontânea (Deci \& Ryan, 2000, 2008). A motivação intrínseca foi analisada como construto único por Ryan \& Deci (2000), Vallerand, Pelletier, Blais, Briere, Senecal, \& Vallieres., (1992), e revelou que essa dimensão possui três subdivisões: Motivação Intrínseca para Saber, para Realizar Coisas e para Experimentar Estímulos (Vallerand, Pelletier, Blais, Briere, Senecal \& Vallieres, 1992). A primeira (Saber), é a ideia de que o impulso à ação decorre do prazer pessoal de realizar novas atividades e/ou obtenção de um novo conhecimento; a segunda (Realizar), ocorre em função da satisfação diante da realização (alcançar ou criar) de novas coisas; a última (Experimentar) ressalta o desejo de participação, de envolvimento nas atividades, sendo estes capazes de estimular sensações agradáveis (Cokley, 2015; Stover, Iglesia, Boubeta \& Liporace, 2012).

A motivação extrínseca, com menor nível de autodeterminação, assume a instrumentalidade da recompensa como estímulo para a ação (Gagné \& Deci, 2005). A dimensão foi subdivida por Deci \& Ryan (2000) em quatro tipos motivacionais: Regulação Externa, Introjetada, Identificada e Integrada, a primeira, sendo a de menor nível de autodeterminação e a última como maior nível, de acordo com o exposto na Figura 1. A primeira (Externa) indica que o sujeito busca agir em função do resultado da ação, demonstrando que a recompensa ou alguma restrição, vai moldando-se de acordo com as contingências externas; a segunda (Introjetada) e a terceira (Identificada) possuem disposições intrínsecas, porém com maior direcionamento em função das consequências. No primeiro caso, há um dissipamento de comportamentos negativos como ansiedade e culpa, que tendem a ser evidenciados por manter o sentimento de valorização de autoestima, expressos em controles auto-impostos, no segundo, busca-se alcançar um objetivo e, com isso, agir por acreditar que a ação é importante para seu alcance; a última (Integrada), agrega a disposição para a ação em função de suas consequências e a assimilação de aspectos externos que disparam a satisfação mais espontânea. A Desmotivação, por sua vez, resulta da ausência de motivação e, por isso, ausência de regulação intencional, com menor nível de autonomia e autodeterminação (Gagné \& Deci, 2005; Ryan \& Deci, 2000). 
A TAD foi estudada no campo educacional (Deci \& Ryan, 2000; Stover et Iglesia, Boubeta \& Liporace 2012). Nesse âmbito, a motivação intrínseca revela impacto positivo na eficácia da aprendizagem, desempenho acadêmico e criatividade, sendo o estímulo a autonomia (autodeterminação) um aspecto associado à análise da qualidade da aprendizagem e à maior participação (Lim \& Chapman, 2015; Stover et Iglesia, Boubeta \& Liporace 2012) 2012). Dessa forma, práticas acadêmicas que restrinjam o exercício da autonomia com pressão por resultados, avaliações padronizadas, recompensas e punições impõem desafio à autodeterminação e podem dificultar o processo de ensino-aprendizagem (Cokley, 2015).

Nesse contexto surge o Modelo de Mensuração da Motivação Discente, desenvolvido por Vallerand, Pelletier, Blais, Briere, Senecal \& Vallieres (1992) que aborda a TAD no âmbito educacional. A Escala de Motivação Acadêmica [EMA] foi testada em vários países, sendo trabalhos recentes o de Akoto (2014) nos Estados Unidos, Gana, Wilkesmann, Fischer, Virgilio (2012) na Alemanha,Zhang, Li, Li, Li \& Zhang . (2016) na China, Stover et al. (2012) na Espanha e Scacchetti, Oliveira e Rufini (2014) e Davoglio, Santos \& Lettnin (2016) no Brasil. Essas pesquisas reforçam que a escala é melhor definida em sete dimensões (Figura 2), distribuídas em três tipos de motivação (Desmotivação, Motivação Intrínseca [MI] e Motivação Extrínseca [ME]), embora alguns resultados apontem a possibilidade de cinco e 3 dimensões. A regulação integrada foi retirada do modelo por apresentar elevadas correlações com as demais motivações extrínsecas (Cokley, 2015).

Inspirados pela leitura de Vallerand, Pelletier, Blais, Briere, Senecal, \& Vallieres, (1992, 1993), Davoglio, Santos \& Lettnin (2016) definiram as dimensões da EMA (Figura 2), como segue:

\begin{tabular}{|c|c|}
\hline Dimensões & Definição \\
\hline $\begin{array}{l}\text { Motivação Intrínseca } \\
\text { (para Saber ou para Conhecer) }\end{array}$ & $\begin{array}{l}0 \text { estudante se engaja em atividades voltadas para a aprendizagem, aprendendo pelo prazer e satisfação } \\
\text { decorrentes de explorar ou entender algo novo. }\end{array}$ \\
\hline $\begin{array}{l}\text { Motivação Intrínseca } \\
\text { (para Realizar) }\end{array}$ & $\begin{array}{l}\text { Realizar ou criar algo, superando os limites conhecidos, produz satisfação e prazer, levando o estudante } \\
\text { a engajar-se nas atividades. }\end{array}$ \\
\hline $\begin{array}{l}\text { Motivação Intrínseca } \\
\text { (para Experimentar) }\end{array}$ & $\begin{array}{l}0 \text { estudante investe nas atividades, a fim de experimentar as sensações estimulantes e desafiadoras, de } \\
\text { natureza sensorial ou estética. }\end{array}$ \\
\hline $\begin{array}{l}\text { Motivação Extrínseca } \\
\text { (Regulação Identificada) }\end{array}$ & $\begin{array}{l}0 \text { estudante tem um nível razoável de percepção da importância de suas ações e aceitação da } \\
\text { responsabilidade própria, envolvendo-se com grau maior de volição e menor sensação de pressão/ } \\
\text { controle externo. }\end{array}$ \\
\hline $\begin{array}{l}\text { Motivação Extrínseca } \\
\text { (Regulação Introjetada) }\end{array}$ & $\begin{array}{l}\text { Baseia-se em contingências externas, sendo controlada por pressões externas, tais como: ofertas } \\
\text { implícitas de engrandecimento ou ameaças implícitas de constrangimento. } 0 \text { estudante age de acordo } \\
\text { com certas normas ou expectativas, visando evitar constrangimentos que geram culpa, vergonha ou } \\
\text { buscando autoavaliação positiva. }\end{array}$ \\
\hline $\begin{array}{l}\text { Motivação Extrínseca } \\
\text { (Regulação Externa) }\end{array}$ & $\begin{array}{l}0 \text { estudante sente-se pressionado pelos demais a agir de determinada forma. Essa pressão se manifesta } \\
\text { na forma de expectativas de recompensa ou punição concreta ou objetiva. }\end{array}$ \\
\hline Desmotivação & $\begin{array}{l}\text { Há interesse ou inspiração, fomentados interna ou externamente, para que o estudante aja em direção a } \\
\text { um objetivo acadêmico, manifestando indiferença ou desinteresse. }\end{array}$ \\
\hline
\end{tabular}

Figura 2. Dimensões e definições da Escala de Motivação Acadêmica

Fonte: Adaptada pelos autores (2017) a partir de Davoglio, Santos \& Lettnin (2016, p. 537). 
Pelo exposto (Figura 2), o envolvimento dos universitários com suas atividades acadêmicas pode variar conforme suas motivações, as quais migram de uma busca de situações prazerosas e estimulantes (Motivações intrínsecas) à atitude instrumental em função do alcance de objetivos advindos da ação, como respeito (avaliação positiva) e emprego (conclusão do curso).

Na concepção de Baumann \& Kuhl (2005) e Gelderen (2010), se os alunos fizerem o curso só porque têm de fazê-lo, porque se sentem obrigados ou pressionados, por exemplo, isso pode condicionar as pessoas ao risco da alienação, ou seja, gera desinvestimento no curso, ao ponto de desencadear desmotivação.

\section{Motivações Empreendedoras}

O estudo do empreendedorismo, em função de sua complexidade e variadas abordagens, apoia-se em diversas áreas do conhecimento, como a economia, psicologia, sociologia e gestão estratégica, por exemplo (Achchuthan \& Nimalathasan, 2014; Sivarajah \&Achchthan, 2013). As contribuições de outras áreas vêm ao encontro da necessidade de aportes teóricos mais consolidados e que subsidiem a discussão de sua epistemologia e fundamentação, na busca de uma maior compreensão e expansão da produção do conhecimento sobre o comportamento empreendedor (Barlach, 2011; Nassif, Ghobril \& Silva, 2010).

Nesse sentido, a investigação da motivação empreendedora é a tônica desta pesquisa, considerando sua influência no sucesso dos negócios, principalmente dos empreendimentos emergentes. Como processo dinâmico, a motivação muda ao longo da vida em função de múltiplos fatores que fornecem um conjunto de valores e crenças que movem o indivíduo à satisfação de necessidades materiais e subjetivas, superação de desafios e garantia de sobrevivência (Sivarajah \&Achchthan, 2013).

A ênfase na perspectiva motivacional tem contribuído com os estudos sobre empreendedorismo, o que gera um maior volume de pesquisas tanto no âmbito nacional como internacional, considerando o aumento de experiências associadas ao protagonismo do Global Entrepreneurship Monitor [GEM] na condução de pesquisas no âmbito internacional sobre a temática (Vale, Corrêa \& Reis, 2014). As pesquisas ainda enfatizam a dicotomia necessidade versus oportunidade como influenciadores da Decisão de empreender (Corrêa \& Vale, 2013). Os empreendedores, por necessidade, iniciam um negócio de forma autônoma com objetivo de garantir o sustento de suas famílias por falta de melhor opção de trabalho. Contudo, esses atores vão além da escassez de empregos, praticando o desenvolvimento de ideias e o crescimento pessoal (Barlach, 2011). Os empreendedores, por oportunidade, iniciam um empreendimento, mesmo quando possuem outras opções de emprego e renda. O novo negócio pode surgir para aumentar a renda familiar e para praticar o desejo de independência, impulsionado pela identificação de uma boa oportunidade de negócio (Gem, 2012).

Seja por necessidade ou por observação de oportunidade, os atores desses processos apostam no empreendedorismo como mecanismo 
de inserção social, profissional e de desenvolvimento de uma carreira, a de "empresário" (Vale, Corrêa \& Reis, 2014). Nesse caminho, Sivapalan \& Balasundaram (2012) e Townsend, Busenitz \& Arthurs (2010) argumentam que aspectos comportamentais instigam a motivação pra empreender, advindos das habilidades pessoais, do contexto econômico, de valores associados à autonomia, independência e reconhecimento, concomitantemente com as expectativas de resultados, superando a dualidade necessidade versus oportunidade.

Atividades empreendedoras podem seguir outras motivações além das questões relacionadas à renda (Rindova, Barry \& Ketchen, 2009). Assim, o empreendedorismo é também associado a um processo emancipatório do ser humano, vinculado às aspirações individuais subjetivas que estimulam o processo de empreender. Nesse caso, a motivação empreendedora colabora não só para a criação de um novo negócio, mas principalmente para mantêlo, considerando que há disposição de energia necessária para driblar as dificuldades e concentrar esforços na busca de sucesso do negócio (Kuratko, Hornsby \& Naffziger, 1997; Robichaud, Mcgraw \& Roger, 2001).

O estudo dos motivos que conduzem a atividade empreendedora considera o desenvolvimento de valores condicionados ao sistema indivíduorelação-ambiente (Sivarajah \& Achchthan, 2013). Além de abordar uma visão racional com foco na necessidade e oportunidade, avalia comportamentos empreendedores no âmbito das emoções e paixões (Barlach, 2011). Assim, as motivações empreendedoras associam-se à necessidade de exercício da autonomia, autoridade, o que induz resistências em relação à trabalhos padronizados, rotineiros (Carvalho \& González, 2006). A criação de um novo negócio, nesse caso, dá margem para o exercício da autonomia e independência (Carvalho, 1997, 2004, Carvalho \& González, 2006), sendo o reconhecimento pessoal, a percepção da instrumentalidade da riqueza e a aprovação social alguns dos aspectos motivacionais preponderantes na Decisão para a criação de uma empresa (Veciana, 1999).

Os motivos que impulsionam os sujeitos ao desenvolvimento de atividades produtivas são objeto de investigação permanente, com contribuições importantes para a área da psicologia. Estudos de McClelland (1961, 1972) e McClelland \& Burnham (1995), por exemplo, associam a investigação dos motivos às necessidades de realização, afiliação e poder, como atributos intrínsecos aos sujeitos. A primeira área enfatiza a superação de desafios para a auto-realização e reconhecimento; a segunda considera a necessidade social de uma rede de relacionamentos positivos; e a terceira, a necessidade do exercício do poder sobre as pessoas do entorno. De todos esses motivos, a necessidade de realização é apontada como aspecto de maior influência (Barba-Sánches \& Atienza-Sahuquillo, 2012; Sivarajah; Achchuthan, 2013).

É possível constatar uma diversidade de fatores que contribuem para as motivações empreendedoras, tendo em vista que "a capacidade de determinados indivíduos em identificar e empreender oportunidades pode estar associada à combinação de seus distintos atributos de natureza pessoal, profissional e social" (Corrêa \& Valle, 2013, p. 16). Ainda na perspectiva de melhor avaliar e explicar esse construto, Carvalho (2004) 
e Carvalho e González (2006) agruparam essas motivações em quatro dimensões conceituais dispostos na Figura 3: necessidade de independência, necessidade de desenvolvimento pessoal, percepção da instrumentalização da riqueza e necessidade de aprovação.

\begin{tabular}{|c|c|c|}
\hline Fatores & Aspectos de avaliação & Autores \\
\hline $\begin{array}{l}\text { Necessidade de } \\
\text { independência }\end{array}$ & $\begin{array}{l}\text { Pôr em prática as minhas próprias ideias; Ter mais autonomia no trabalho; Ter } \\
\text { uma maior flexibilidade na vida privada; Tirar vantagens das novas tecnologias. }\end{array}$ & \\
\hline $\begin{array}{l}\text { Necessidade de } \\
\text { desenvolvimento } \\
\text { pessoal }\end{array}$ & $\begin{array}{l}\text { Implementar um negócio de sucesso; Implementar um negócio inovador; } \\
\text { Realização pessoal. }\end{array}$ & $\begin{array}{l}\text { Carvalho (1997); Pereira (2001); } \\
\text { Dubini (1988); Scheinberg e }\end{array}$ \\
\hline $\begin{array}{l}\text { Percepção da } \\
\text { instrumentalidade da } \\
\text { riqueza }\end{array}$ & $\begin{array}{l}\text { Ter mais rendimentos; Ser rico; Fugir ao desemprego; Ter mais segurança no } \\
\text { futuro; Beneficiar de subsídios para a criação de uma empresa. }\end{array}$ & $\begin{array}{l}\text { MacMillan (1988); Alänge e } \\
\text { Scheinberg (1988); Jesuíno, } \\
\text { Reis e Cruz (1988) }\end{array}$ \\
\hline $\begin{array}{l}\text { Necessidade de } \\
\text { aprovação }\end{array}$ & $\begin{array}{l}\text { Ganhar prestígio na sociedade; Realizar algo e ser reconhecido por isso; Ter } \\
\text { mais influência na sociedade; Ser mais respeitado pelos meus amigos e colegas; } \\
\text { Seguir o exemplo de empresários que admiro; Dar continuidade à tradição } \\
\text { empresarial da minha família. }\end{array}$ & \\
\hline
\end{tabular}

Figura 3. Instrumento para avaliação das motivações empreendedoras

Fonte: Adaptada pelos autores (2017) a partir de Carvalho (2004, p. 73).

A necessidade de independência ou de autonomia associa-se à busca de realização pessoal para dar substância às próprias ideias no processo criativo (Carvalho, 2004). A necessidade de desenvolvimento pessoal, por sua vez, é concebida com suporte nos estudos de McClelland, Atkinson, Clark \& Lowell (1953) e McClelland \& Burnham (1995), ressaltando a busca pela excelência no desenvolvimento das atividades para alcançar a realização pessoal e profissional. O terceiro fator, a instrumentalidade da riqueza, reforça a posição de que a obtenção de lucro é estímulo para a criação de novas empresas, mesmo que não seja o principal fator motivacional (Carvalho, 2004). Por último, a necessidade de aprovação reporta ao reconhecimento social do empresário como figura importante na sociedade, mesmo que esse fator seja particularmente influenciado pela cultura da sociedade (Carvalho, 1997, 2004, Carvalho \& González, 2006).

Em resumo, na perspectiva de Carvalho (2004) e Carvalho \& González (2006), quanto mais elevadas forem as motivações empreendedoras designadas por necessidade de independência ou autonomia, necessidade de desenvolvimento pessoal, percepção da instrumentalidade da riqueza e necessidade de aprovação, maior será a probabilidade de o indivíduo ter uma intenção favorável relativa à alternativa de criar a sua própria empresa.

\section{Método}

A pesquisa possui natureza quantitativa, haja vista a finalidade de descrever características de determinada população ou fenômeno afim de inferir relações por meio do teste de hipóteses, seguindo o procedimento de análise estrutural (Hair, Hult, Ringle \& Sarstedt, 2014). 
O universo da pesquisa de campo foi composto por 245 universitários graduandos em Administração de Empresas, pertencentes a sete Instituições de Ensino Superior, situadas em três cidades do Nordeste. A coleta foi realizada nos meses de novembro de 2016 a abril de 2017, presencialmente, com apoio de professores na condução da aplicação. Além disso, realizou-se também a coleta virtualmente, por meio de planilha elaborada no programa Google Docs.

Em relação à representatividade amostral, seguiu-se a recomendação de Rigle, Silva \& Bido (2014) no que tange à utilização do software $G^{*} P o w e r$ (versão 3.1.9.2) para estimar o tamanho mínimo a ser utilizado em função do poder do teste (power) e do efeito $\left(\mathrm{f}^{2}\right)$. Para aferir o tamanho amostral utilizouse o teste a priori, com base nos parâmetros (power: 80\%, f2: 15\% (mediano) e significância: $5 \%$, com 7 variáveis preditoras, considerando as setas que chegam à Variável Latente Sugestões Criativas e teste Regressão linear múltipla-modelo randômico (Faulet, Erdfelder \& Lang, 2007). Com este teste, o tamanho amostral resultou em 92, com um $\mathrm{R}^{2}$ previsto para o modelo de $15 \%$, o que implica em poder explicativo médio da variável dependente pelas variáveis independentes (Cohen, 1988). Com os mesmos parâmetros, o teste post hoc para uma amostra de 245 resultou em um poder de teste de 0,999.

Ainda de forma a priori utilizou-se o teste Linear multiple regression: fixed model, $\mathrm{R}^{2}$ deviation from zero para verificar se a hipótese nula assume a condição de que o valor da $R^{2}$ é igual a zero ou se a hipótese alternativa assume que $\circ \mathrm{R}^{2}$ diferente de zero. Assumiu-se os mesmos parâmetros de poder, efeito e significância. Sendo assim, o teste indicou um tamanho amostral de 103. A análise post hoc (tamanho amostral de 245) com base nesse teste, informa um poder de 0,997. Dessa forma, os resultados via $G^{\star}$ Power demonstraram que a amostra foi suficiente para uma melhor robustez das análises realizadas do modelo estrutural (Faul et Erdfelder \& Lang, 2007; Rigle, Silva \& Bido, 2014).

No tangente ao instrumento, utilizou-se um questionário estruturado, autoaplicável, composto por 46 itens de duas escalas Likert de 10 pontos, em que Discordo Totalmente assume o valor 1 e Concordo Totalmente, 10. A pontuação da escala foi escolhida em função da familiaridade dos universitários com a pontuação de 0-10 em suas avaliações acadêmicas (Apêndice A).

A primeira corresponde à Escala de Motivação Acadêmica, elaborada por Vallerand e et al. (1989) e Vallerand et al. (1992), validadas no Brasil por Sobral (2003) e Davoglio, Santos \& Lettnin (2016), composta por 28 itens, dispostos em sete dimensões (Desmotivação, Regulação Externa, Regulação Introjetada, Regulação Identificada, Motivação a Experimentar, a Realizar e a Saber). A segunda, a Escala de Motivações Empreendedoras, elaborada por Carvalho (2004, 2006), possui 18 itens dispostos em quatro dimensões (Necessidade de Independência, Necessidade de Desenvolvimento Pessoal, Percepção da Instrumentalidade da Riqueza, Necessidade de Aprovação.

Preliminarmente à análise, o tratamento prévio dos dados indicou a existência de demissing values, porém, foram substituídos pela média, uma vez que não contabilizaram menos de $5 \%$ da amostra (Hair, Hult, Ring \& Sarstedt, 2014). 
O modelo conceitual proposto foi estimado pelo método Partial Least Squares Path Modeling (PLS-PM), baseado em covariância, cuja escolha se baseou na possibilidade de testar relações entre variáveis latentes sem a suposição de normalidade multivariada (Hair, Hult, Ring \& Sarstedt sendo também adequado a estudos exploratórios (Chin \& Newsted, 1999). Para a análise, utilizou-se o software Smart PLS (versão 2.0 M3 Beta).

A análise, conforme parametriza Hair, Hult, Ring \& Sarstedt (2014), foi realizada em duas etapas: a primeira, avaliação do modelo de mensuração, considerando os procedimentos de ajustamentos pela confiabilidade composta (composite reliability), validade convergente (variance extracted), confiabilidade do indicador (indicator reliability) e validade discriminante (discriminant validity). A segunda foi realizada por meio da avaliação do modelo estrutural, pelos ajustamentos dos coeficientes de determinação $\left(R^{2}\right)$, relevância preditiva $\left(Q^{2}\right)$, tamanho e significância dos coeficientes de caminho, tamanhos do efeito e (f2) (q2). Por fim, se estabeleceu o teste de significância das relações hipotetizadas.

A Figura4 apresenta as Variáveis Latentes do Modelo Estrutural a ser testado.
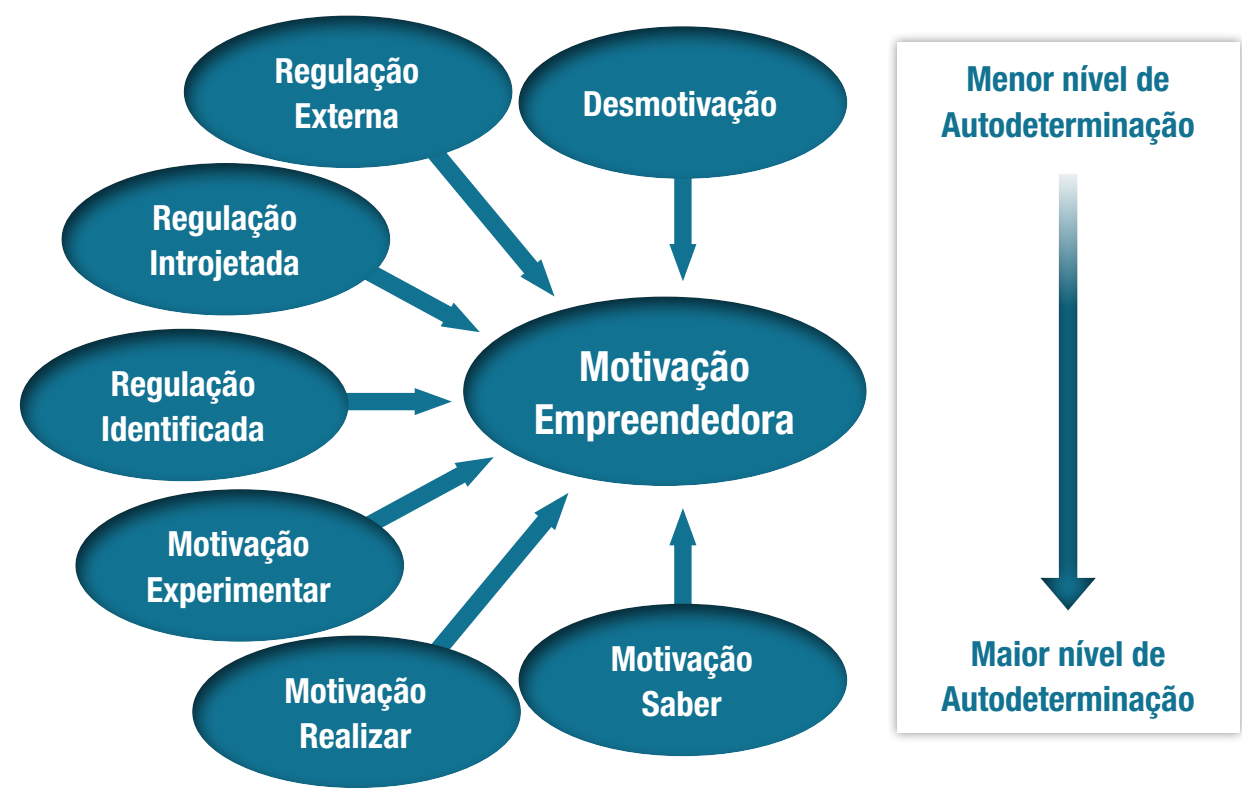

Com base na leitura de Hyttiet, Stenholm, Heinonen \& Seikkula-Leino (2010) e Morris, Shirokova \& Tsukanova (2017):

1) $\mathrm{H} 1, \mathrm{H} 2, \mathrm{H} 3, \mathrm{H} 4-$ influenciam positivamente as motivações empreendedoras

2) H5, H6, H7- influenciam positivamente as motivações empreendedoras

Figura 4. Modelo do estudo*

Fonte: Elaborada pelos autores (2017).

Nota: *A Motivação Empreendedora é modelada como variável de segunda ordem.

A figura 4 ilustra as seguintes hipóteses: H1, a Variável Desmotivação influencia positivamente as motivações empreendedoras; H2, a Variável Regulação Externa influencia positivamente as motivações empreendedoras; H3, a Variável Regulação Introjetada influencia positivamente as motivações empreendedoras; H4, a Variável Regulação Identificada influencia positivamente as motivações empreendedoras; H5, a Variável Motivação de Experimentar influencia positivamente as motivações empreendedoras; H6, a Variável Motivação de Realiza influencia positivamente as motivações empreendedoras; por fim, H7, a Variável Motivação de Saber, influencia positivamente as motivações empreendedoras. 
As hipóteses de pesquisa foram aferidas por meio o modelo estrutural, estimado pelo método Partial Least Squares Path Modeling [PLS-PM], baseado em covariância, cuja escolha se baseou na possibilidade de testar relações entre variáveis latentes sem a suposição de normalidade multivariada (Hair, Hult, Ring \& Sarstedt (2014). Em complemento adequou-se a outros exploratórios (Chin \& Newsted, 1999). Para a análise, utilizou-se o software Smart PLS (versão 2.0 M3 Beta).

\section{Apresentação dos Resultados}

Para a avaliação do modelo de mensuração, recomenda-se a análise da Validade Convergente, obtida pela Average Variance Extracted [AVEs], sob o critério de Fornell \& Larcker (1981). Dessa forma, os valores das AVEs devem ser maiores que 0,50 (AVE > 0,50), indicando que o constructo explica mais da metade da variância dos indicadores. Deacordo com a Tabela 1, apenas a Variável Instrumentalidade da Riqueza [IR] possui AVE um pouco abaixo de recomendado (0,480).A Consistência interna (alpha de Cronbach) e a Confiabilidade Composta (Reliability composite), por sua vez, seguindo a orientação de Hair, Hult, Ring \& Sarstedt (2014), devem assumir, no primeiro caso, valores acima de 0,60 e 0,70 (considerados adequados em pesquisas exploratórias) e, no segundo, valores de 0,70 e 0,95 (são considerados satisfatórios).

O modelo de mensuração possui consistência interna para a maioria dos constructos (alpha $>0,7$ ). Em relação à Confiabilidade Composta, todos as variáveis atendem ao critério $0,7<\mathrm{CC}<0,95$. A Validade Discriminante foi avaliada por meio das raízes quadradas das AVEs, que devem ser maiores que as correlações entre os constructos (Fornell \& Larcker, 1981). Assim, esses compartilham maior variância com seus indicadores do que com outros constructos, sendo, então, independentes uns dos outros. Pela Tabela 1, observa-se a Validade Discriminante do estudo (2 $\sqrt{\text { AVE }}>$ correlações de Pearson entre os construtos).

Tabela 1. Matriz de correlações entre as variáveis latentes de primeira ordem

\begin{tabular}{lccccccccccc}
\hline & $(\mathbf{1})$ & $\mathbf{( 2 )}$ & $\mathbf{( 3 )}$ & $\mathbf{( 4 )}$ & $\mathbf{( 5 )}$ & $\mathbf{( 6 )}$ & $\mathbf{( 7 )}$ & $\mathbf{( 8 )}$ & $\mathbf{( 9 )}$ & $\mathbf{( 1 0 )}$ & $\mathbf{( 1 1 )}$ \\
\hline 1. Necessidade de Aprovação & 0,778 & & & & & & & & & & \\
2. Instrumentalidade da Riqueza & 0,653 & 0,693 & & & & & & & & & \\
3. Necessidade de Independência & 0,396 & 0,563 & 0,773 & & & & & & & & \\
4. Desenvolvimento Pessoal & 0,508 & 0,422 & 0,555 & 0,842 & & & & & & & \\
5. Desmotivação & 0,244 & 0,215 & 0,023 & $-0,007$ & 0,752 & & & & & & \\
6. Motivação Extrínseca 1 & 0,379 & 0,470 & 0,377 & 0,250 & $-0,074$ & 0,753 & & & & & \\
7. Motivação Extrínseca 2 & 0,514 & 0,414 & 0,462 & 0,350 & 0,150 & 0,586 & 0,836 & & & & \\
8. Motivação Extrínseca 3 & 0,361 & 0,237 & 0,384 & 0,385 & $-0,170$ & 0,539 & 0,558 & 0,749 & & & \\
9. Motivação Intrínseca 1 & 0,362 & 0,238 & 0,349 & 0,316 & 0,039 & 0,443 & 0,649 & 0,635 & 0,799 & & \\
10. Motivação Intrínseca 2 & 0,405 & 0,280 & 0,416 & 0,349 & $-0,033$ & 0,573 & 0,820 & 0,628 & 0,723 & 0,828 & \\
11. Motivação Intrínseca 3 & 0,377 & 0,234 & 0,359 & 0,433 & $-0,106$ & 0,576 & 0,621 & 0,742 & 0,748 & 0,729 & 0,822 \\
\hline Alfa & 0,863 & 0,725 & 0,772 & 0,790 & 0,758 & 0,740 & 0,857 & 0,739 & 0,812 & 0,848 & 0,842 \\
AVE & 0,606 & 0,480 & 0,598 & 0,790 & 0,565 & 0,567 & 0,700 & 0,561 & 0,638 & 0,686 & 0,676 \\
CC & 0,899 & 0,820 & 0,855 & 0,879 & 0,837 & 0,837 & 0,903 & 0,835 & 0,876 & 0,897 & 0,893 \\
\hline
\end{tabular}

Fonte: Elaborada pelos autores com base nos dados da pesquisa (2017).

Legenda: Alfa: Cronbach's Alpha; AVE: Average Variance Extracted; CC: Composite Reliability.

Nota 1: Valores em negrito na diagonal são a raiz quadrada da variância média extraída.

Nota 2: Motivação Empreendedora é modelada como variável de segunda ordem.

Nota 3: Variáveis de 1 a 4: Motivação Empreendedora; Variáveis de 5 a 11: Motivação Acadêmica. 
Da mesma forma, a Tabela 2 demostra a Validade Discriminante dos construtos do Modelo Estrutural.

Tabela 2. Matriz de correlações entre as Variáveis Latentes do modelo estrutural

\begin{tabular}{lcccccccc}
\hline & $(\mathbf{2})$ & $\mathbf{( 3 )}$ & $\mathbf{( 4 )}$ & $\mathbf{( 5 )}$ & $\mathbf{( 6 )}$ & $\mathbf{( 7 )}$ & $\mathbf{( 8 )}$ & (9) \\
\hline 1. Desmotivação & 0,752 & & & & & & & \\
2. Motivação Extrínseca 1 & $-0,074$ & 0,753 & & & & & & \\
3. Motivação 4. Extrínseca 2 & 0,150 & 0,586 & 0,836 & & & & & \\
5. Motivação Extrínseca 3 & $-0,170$ & 0,539 & 0,558 & 0,749 & & & & \\
6. Motivação Intrínseca 1 & 0,039 & 0,443 & 0,649 & 0,635 & 0,799 & & & \\
7. Motivação Intrínseca 2 & $-0,033$ & 0,573 & 0,820 & 0,628 & 0,723 & 0,828 & & \\
8. Motivação Intrínseca 3 & $-0,106$ & 0,576 & 0,621 & 0,742 & 0,748 & 0,729 & 0,822 & \\
9. Motivação Empreendedora & 0,176 & 0,467 & 0,557 & 0,425 & 0,400 & 0,457 & 0,435 & 0,794 \\
\hline Alfa & 0,758 & 0,740 & 0,857 & 0,739 & 0,812 & 0,848 & 0,842 & 0,899 \\
AVE & 0,565 & 0,567 & 0,700 & 0,561 & 0,638 & 0,686 & 0,676 & 0,632 \\
CC & 0,837 & 0,837 & 0,903 & 0,835 & 0,876 & 0,897 & 0,893 & 0,914 \\
\hline
\end{tabular}

Fonte: Elaborada pelos autores com base nos dados da pesquisa (2017).

Nota 1: Valores em negrito na diagonal são a raiz quadrada da variância média extraída.

Nota 2: Motivação Empreendedora é modelada como variável de segunda ordem.

Avaliou-se também as cargas fatoriais do modelo de análise (Figura 5). Apenas 1 indicador foi retirado do modelo (Indicador NA6 - Necessidade de Aprovação), considerando que apresentou carga fatorial próximo a 0,4. Todos os demais indicadores foram mantidos, haja vista valores acima de 0,58 . As cargas entre 0,58 e 0,7 foram mantidas para não prejudicar a validade de conteúdo do construto - cada item é uma dimensão do Variável Latente em análise) (Savelsbergh, Van Der Eijden \& Poell, 2009).

No que tange a capacidade explicativa do modelo, tem-se como parâmetro o Coeficiente Estrutural $\left[R^{2}\right]$, que representa os efeitos combinados das variáveis exógenas sobre as variáveis endógenas, ou seja, quantidade de variação no construto endógeno que é explicado pelos construtos exógenos (Hair, Hult, Ring \& Sarstedt (2014). Considerando que seus valores variam de 0 a 1, Cohen (1988), em pesquisas na área de ciências sociais e comportamentais, sugere que $R^{2}=2 \%$, indicando efeito pequeno, enquanto $R^{2}=13 \%$, um efeito médio e $R^{2}=26 \%$, um efeito grande. 


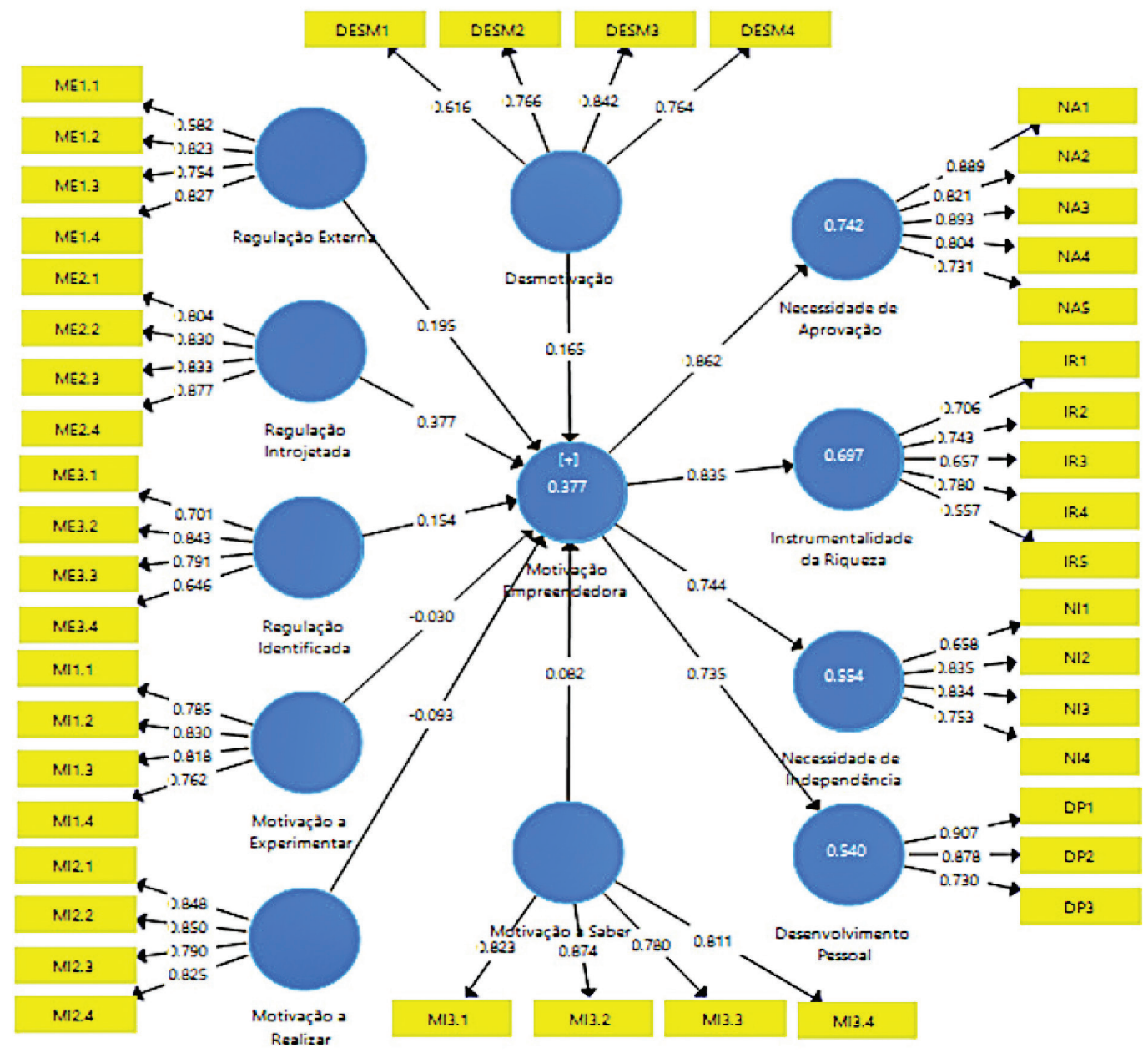

Figura 5. Cargas Fatoriais e os Coeficientes Estruturais ( $\beta$ )do Modelo Mensuração Fonte: Elaborada pelos autores com base nos dados da pesquisa (2017).

Antes de avaliar o $\mathrm{R}^{2}$ do modelo, as relações hipotetizadas (Figura2) foram testadas, afim de verificar a significância dos coeficientes padronizados (path coefficients) por meio do procedimento Bootstrapping (técnica de reamostragem) no Smart PLS com 500 amostras envolvendo 29 variáveis. Assim, para valores acima de 1,96 para o teste t de Student e $p$-value menor ou igual a 0,05, as relações são significantes.

Tabela 3. Teste de significância das relações hipotetizadas na motivação empreendedora.

\begin{tabular}{lcccc}
\hline & $\boldsymbol{\beta}$ & Erro Padrão & T Statistics (IO/STDEVI) & p-values \\
\hline Desmotivação & 0,166 & 0,047 & 3,534 & 0,000 \\
Motivação Extrínseca 1 & 0,195 & 0,079 & 2,477 & 0,014 \\
Motivação Extrínseca 2 & 0,977 & 0,089 & 4,226 & 0,000 \\
Motivação Extrínseca 3 & 0,154 & 0,103 & 1,488 & 0,137 \\
Motivação Intrínseca 1 & $-0,029$ & 0,072 & 0,409 & 0,683 \\
Motivação Intrínseca 2 & $-0,093$ & 0,119 & 0,785 & 0,433 \\
Motivação Intrínseca 3 & 0,082 & 0,107 & 0,774 & 0,439 \\
\hline
\end{tabular}

Legenda: $\beta=$ coeficiente estrutural; $f^{2}=$ tamanho do efeito.

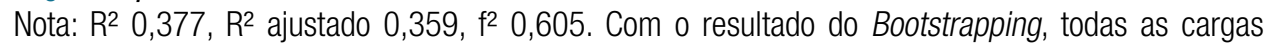
fatoriais revelaram significância (valores-t superiores a 2,766). 
Pela análise de bootstrapping dos sete preditores da Motivação Empreendedora, a Desmotivação $(\beta=0,166 ; \quad p<0,005), \quad$ a Regulação Externa $(\beta=0,195 ; p<0,005)$ e a Regulação Introjetada $(\beta=0,977 ; p<0,005)$ mostraram-se significantes. Assim, os três construtos explicam $R^{2} 0,359 \%$ da variância da Motivação Empreendedora. A Regulação Introjetada possui o maior coeficiente de determinação, o que faz inferir sua maior influência em relação às Motivações Empreendedoras.

O teste blindfolding aponta para a capacidade preditiva do modelo testado (Tabela 4), tendo como referência indicadores $\mathrm{Q}^{2}$ acima de zero. $\mathrm{Na}$ Tabela 4 são apresentados os indicadores de relevância preditiva $\left(Q^{2}\right)$, ou critério de Stoner-Geisser, o qual avalia a acurácia do modelo e utilidade do construto $\left(f^{2}\right)$ na formação do modelo proposto. Ressalta-se que os indicadores de $\mathrm{f}^{2}$ sinalizam para a utilidade do construto na formação do modelo, objetivando verificar se a omissão do construto resultaria em alteração significativa no coeficiente de determinação do modelo $\left(R^{2}\right)$. O tamanho do efeito $\left(\mathrm{f}^{2}\right)$, considera os valores 0,02(baixa utilidade), 0,15(média utilidade) e 0,35 (grande utilidade) $\left(f^{2}=R^{2} /\left(1-R^{2}\right)\right)$ (Cohen, 1988).

Tabela 4. Relevância preditiva e utilidade do construto

\begin{tabular}{|c|c|c|}
\hline Variável & Q2 & f2 \\
\hline Necessidade de Aprovação & 0,442 & 0,458 \\
\hline Instrumentalidade da Riqueza & 0,326 & 0,212 \\
\hline Necessidade de Independência & 0,317 & 0,325 \\
\hline Desenvolvimento Pessoal & 0,371 & 0,416 \\
\hline Desmotivação & & 0,279 \\
\hline Motivação Extrínseca 1 & & 0,289 \\
\hline Motivação Extrínseca 2 & & 0,488 \\
\hline Motivação Extrínseca 3 & & 0,254 \\
\hline Motivação Intrínseca 1 & & 0,388 \\
\hline Motivação Intrínseca 2 & & 0,467 \\
\hline Motivação Intrínseca 3 & & 0,453 \\
\hline Motivação Empreendedora & 0,134 & 0,307 \\
\hline
\end{tabular}

Fonte: Elaborada pelos autores com base nos dados da pesquisa (2017).

Nota: Resultado obtido pelo teste blindfolding

$\mathrm{Na}$ análise percebe-se que a Regulação Introjetada $\left(f^{2}=0,488\right)$ é a dimensão da Motivação com maior utilidade no modelo, apresentando efeito grande sobre a Motivação Empreendedor (Cohen, 1988). No caso da relevância preditiva de um modelo perfeito $\left(Q^{2}=1\right)$, a Necessidade de Aprovação $\left(Q^{2}=0,442\right)$ e o Desenvolvimento Pessoal $\left(Q^{2}=0,371\right)$ são as variáveis melhor explicadas pelo modelo.

\section{Discussão}

O estudo avança nas pesquisas de Hytti, Stenholm, Heinonen \& SeikkulaLeino (2010) e Morris, Shirokova \& Tsukanova (2017), por apresentar o mesmo direcionamento das relações encontradas nos seus achados entre 
Motivação para aprender e Eficácia do aprendizado por meio da geração de uma ideia de negócio, neste estudo, alicerçadas na relação entre Motivação Acadêmica e Motivação Empreendedora.

No que tange a relação positiva entre Motivação Extrínseca e Motivações Empreendedoras, das três dimensões a Regulação Introjetada foi a que apresentou maior relação, indicando que universitários que se envolvem academicamente com base em expectativas definidoras do seu autoconceito (aprovação, confiança, inteligência) (Davoglio, Santos \& Lettnin, 2016) são aqueles que possuem disposição ao empreendedorismo. Essa leitura pode alinhar-se à necessidade de aprovação social, atrelado ao valor cultural da Figura do empresário (Carvalho, 1997, 2004, Carvalho \& González, 2006), portanto, uma inclinação subjetiva, vinculada à busca de afirmação social.

A Regulação Externa, que se baseia diretamente na instrumentalidade da recompensa (Gagné \& Deci, 2005), indica que os respondentes que manifestam envolvimento acadêmico com base em pressões externas, se moldam com base em contingências externas (ser aprovado, ter o título), e também são aqueles que possuem disposição ao empreendedorismo. Nesse caso, o curso é avaliado em função do que pode agregar em termos de remuneração, boa vida e prestígio no futuro, não pelo conhecimento apreendido (aprende-se para passar).

Em relação à Desmotivação, caracterizada pela ausência de regulação intencional (Gagné \& Deci, 2005; Ryan \& Deci, 2000), pode-se supor que sua relação com a Motivação Empreendedora se deva ao fato de que o curso deixa de ser analisado como algo importante e necessário para empreender. Essa é a situação em que não se sabe o sentido de ir à Universidade, considerando-a uma perda de tempo. De acordo com Hyttiet, Stenholm, Heinonen \& Seikkula-Leino (2010) Morris, Shirokova \& Tsukanova (2017), essa pode ser a posição de quem já tem alguma experiência com empreendedorismo, ou mesmo uma autopercepção empreendedora, o que favorece a crença de que o curso não agregará em nada.

A Motivação Identificada, com o maior nível de autodeterminação, bem como as três dimensões da Motivação Intrínseca (Experimentar, Realizar, Saber) não se relacionaram a Motivações Empreendedoras. Nesse caso, acadêmicos que se envolvem no processo de aprendizagem por considerála uma atividade prazerosa, gratificante por si só, ou seja, com maiores níveis de autodeterminação acadêmica (Davoglio, Santos \& Lettnin, 2016), não revelam motivações empreendedoras.

Tal leitura invoca a necessidade de melhor equacionar necessidades individuais, amparadas pelas distintas disposições motivacionais e formação empreendedora com objetivo de se obter maior eficácia da aprendizagem (aprender para a vida, para criar e manter o negócio). Nesse caminho, cursos e programas podem não estar alinhados às reais expectativas/motivações dos acadêmicos no fomento da sua capacidade em identificar e empreender oportunidades (Hyttiet, Stenholm, Heinonen \&Seikkula-Leino, 2010). Com isso, avigora-se, assim, o foco na sua formação acadêmica sem considerar as necessidades que promulgariam a uma motivação empreendedora por meio do desenvolvimento das habilidades requeridas para geração de um negócio. 
Para tanto, com o intuito de aumentar a motivação empreendedora, tem-se que os cursos e programas devem adotar projetos pedagógicos com ênfase no desenvolvimento das habilidades psicológicas e sociais empreendedoras dos alunos, estimulando, em especial, o fator emocional e o pensamento crítico (Farhangmehr, Gonçalves \& Sarmento, 2016). Nesse ponto, faz-se jus a uma metodologia pedagógica amparada ao contexto da aprendizagem esperada (Rocha \& Freitas, 2014), tendo como princípio a multidisciplinaridade peculiar à formação empreendedora (Boyles, 2012). Como exemplo, tem-se o valor da prática deliberada e da aprendizagem experiencial como elementos centrais de um programa de empreendedorismo (Morris, Kuratko \& Pryor, 2014, Neck,Greene \& Brush, 2014).

\section{Conclusão}

Diante da problemática levantada, o estudo faz uso do teste de relações com base em sete hipóteses, relacionando diretamente as sete dimensões da Escala de Motivação Acadêmica (Desmotivação, Regulação Externa, Regulação Introjetada, Regulação Identificada, Motivação a Experimentar, a Realizar e a Saber) à Motivação Empreendedora.

Os resultados seguem o mesmo direcionamento das relações hipotetizadas por Hytti, Stenholm, Heinonen \& Seikkula-Leino (2010) e Morris, Shirokova \& Tsukanova (2017), porém avançando no sentido de considerar que o aprendizado não supre as reais expectativas e motivações dos acadêmicos para empreender. Assim, das relações estabelecidas entre os níveis de autodeterminação manifestas pela Motivação Acadêmica e Motivação Empreendedora, foi identificada a relação entre Desmotivação Acadêmica e Motivações Empreendedoras, uma vez que duas das dimensões da Motivação Extrínseca (Regulação Externa e Regulação Introjetada), relacionaram-se às Motivações Empreendedoras. Nesse caso, o autoconceito (Regulação Introjetada-maior explicação) determinado pelo envolvimento acadêmico com base em expectativas de valoração externa positiva pode indicar a necessidade de aprovação social agregada ao empreendedorismo, sendo esse valorado culturalmente. Ademais, os níveis de autodeterminação elevados não se relacionaram às Motivações Empreendedoras.

O estudo agrega para a academia quando direciona que cursos e programas que visem a formação empreendedora conduzam seus objetivos de forma a moldar-se às motivações prévias dos alunos, a fim de obter maior eficácia pedagógica. E, sendo possível identificar universitários em diferentes motivações, tem-se a probabilidade de também auxiliar docentes no planejamento de atividades direcionadas aos grupos de alunos com perspectivas de formação próximas.

Nesse aspecto, pensar em termos motivacionais pode favorecer aos cursos e programas maior atratividade àqueles que buscam empreender, demostrando que a formação universitária conduz a outros saberes necessários não apenas para empreender, embora consiga formar bons empreendedores. 
Entende-se que a congruência de formação e novos saberes norteia outros conhecimentos balizadores da relação com a sociedade, assim, favorecem na efetividade da formação do aluno, tanto acadêmica como profissionalmente.

Potencialmente, atividades extra-curriculares como competições de planos de negócios, estágios, incubadoras, programas de coaching, séries de palestrantes, clubes de empreendedorismo, comunidades de aprendizado e, dentre outras, podem vir a proporcionar, aos alunos de níveis de autodeterminação elevados, oportunidades de interagir com especialistas de distintas universidades, empreendedores e outros profissionais.Por conseguinte, promove-se o processo de ensino-aprendizagem da formação empreendedora no seio da universidade.

No contraponto, não se pode negligenciar o estímulo ao abandono da Universidade, lócus de difusão de saber/conhecimento, na tentativa de descaracterizar a formação acadêmica como motriz para uma maior capacitação profissional empreendedora. Portanto, propõe-se que estratégias pedagógicas emergentes que combatam a situação acima sejam planejadas, a fim de avigorar que a geração do conhecimento apreendido na formação acadêmica dos alunos, dentro das Universidades, seja de suma importância para que se capacite o empreendedorismo. Sendo assim, um novo olhar permearia o empresariado, pois os projetos pedagógicos dos cursos e programas seriam vistos como parceiros fortes e aliados do fomento de um perfil empreendedor mais completo por parte dos alunos.

A pesquisa limita-se ao contexto de Instituições de Ensino Superior de uma região do Brasil, o que pode refletir questões culturais que podem ter influências nos resultados. A não distinção de Instituições privadas e públicas nesta pesquisa também representa uma limitação de estudo, pois a experiência de trabalho e o tempo destinado aos estudos podem revelar diferentes tipos de envolvimento com o curso.

Pesquisas futuras comparticipantes de outras regiões de país podem ampliar a amostra, bem como podem estabelecer comparativos com outros países. Além disso, também possibilitam identificar se características sócio demográficas fazem diferir os resultados, assim como a experiência prévia com empreendedorismo e/ou emprego. Sugere-se, por fim, que análises qualitativas busquem indicar como estabelecer relações positivas entre maiores níveis de autodeterminação no âmbito acadêmico com motivações e atitudes empreendedoras, haja vista que com essa relação se supõem maior qualidade da formação e melhoria nos índices relacionados ao empreendedorismo.

\section{Referências}

Achchuthan, S., \& Nimalathasan, B. (2012). Level of entrepreneurial intention of the management undergraduates in the University of Jaffna, Sri Lanka: scholars and undergraduates' perspective. South Asian Academic Research Journals, 2(10), 24-42. 
Cross Cultural Management, 21(1), 104-125.

Alderfer, C. P. (1969). An empirical test of a new theory of human needs. Organizational Behavior and Human Performance, 4(2), 142-175.

Athayde, R. (2009). Measuring Enterprise Potential in Young People. Entrepreneurship theory and practice, 33(2),481-500.

Bandura, A. (1999). A sociocognitive analysis of substance abuse: An agentic perspective. Psychological Science, 10, 214-217.

Barlach, L. (2011). Empreendedorismo ou profissão: Um desafio para orientadores(as). Revista Brasileira de Orientação Profissional, 12, 119-125.

Barros, A. F.de. (2015). Crisis, What Crisis? - The Life Goals of University-aged Students During an Ongoing Economic and Financial Crisis. Curr Psychol, 34,434-446.

Baumann, N., \& Kuhl, J. (2005). How to resist temptation: The effects of external control versus autonomy support on self-regulatory dynamics. Journal of Personality, 73(2), 443-470.

Boyles, T. (2012). 21st century knowledge, skills, and abilities and entrepreneurial competence: a model for undergraduate entrepreneurship education. Journal of Entrepreneurship Education, 15(1), 41-55.

Caray, C., \& Matlay, H. (2007). Entrepreneurs as Educators: The Case of the Creative Industries in the UK. Industry and Higher Education, 21(6), 436-446.

Chin, W. W., \& Newsted, P. R. (1999). Structural equation modeling analysis with small samples using partial least squares. In R. H. Hoyle (Ed.), Statistical strategies for small sample research (pp. 307-341). Thousand Oaks: CA: Sage Publications.

Carvalho, P. M. R. (1997). Características e motivações dos empresários: O caso dos fundadores de pequenos negócios na cidade da Guarda. Anais Universitários, Série de Ciências Sociais e Humanas, 8,107-136.

Carvalho, P. M. R. de., \& González, L. (2006). Modelo explicativo sobre a intenção empreendedora. Comportamento Organizacional e Gestão, 12(1), 43-65.

Carvalho, P. M. R. (2004). Competências para o Entrepreneurship: Um modelo explicativo (Tese de doutorado). Universidade de Salamanca, Salamanca, Espanha. Recuperado de http://repositorio.ipcb.pt/ handle/10400.11/396

Cohen, J. (1988). Statistical power analysis for the behavioral sciences. New York: Academic Press.

Cokley, K. O. (2015). Confirmatory factor analysis of the academic motivation scale with black college students. Measurement and Evaluation in Counseling and Development, 2(48),124- 139.

Colette, H. (2015). Entrepreneurship education evaluation: revisiting Storey to hunt for the heffalump, Education + Training, 57(8/9), 816-833.

Corrêa, S., \& Vale, G. M. V. (2013, outubro/dezembro). A dinâmica das motivações empreendedoras: uma investigação retrospectiva. Pretexto, Belo Horizonte, 14(4), $11-28$.

Davoglio, T. R., Santos, B. S., \& Lettnin, C. de C. (2016, julho/ setembro). Validação da Escala de Motivação Acadêmica em universitários brasileiros. Ensaio: Avaliação e Políticas Públicas em Educação, Rio de Janeiro, 24,522-545. 
Deci, E. L., \& Ryan, R. M. (2000). The what and why of goal pursuits: human needs and the self-determination of behavior. Psychological Inquiry, 11, 227-268.

Deci, E. L., \& Ryan, R. M. (2008). Facilitating optimal motivation and psychological well-being across lifes domains. Canadian Psychology, 49(1), 14-23.

Dubini, P. (1988). The influence of motivations and environment on business startups: some hints for public policies. Journal of Business Venturing, 4, 11-26.

Farhangmehr, M., Gonçalves, P., \& Sarmento, M. (2016). Predicting entrepreneurial motivation among university students: The role of entrepreneurship education. Education + Training, 58(7/8), 861-881.

Ferreira, A., Loiola, E., \& Guedes Gondim, S. (2016). MOTIVATIONS, BUSINESS PLANNING, AND RISK MANAGEMENT: ENTREPRENEURSHIP AMONG UNIVERSITY STUDENTS. INMR - Innovation \& Management Review, 14(2), 140-150.

Fischer, H. Virgílio, A., \& Wilkesmann, U. (2012) Academic motivation of students: the german case. Discussion papers des Zentrums fur Hochschul Bildung, (2), p.1-20.

Fornell, C., \& Larcker, D. F. (1981). Evaluating structural equation models with unobservable variables and measurement error. Journal of Marketing Research, 18(1), 39-50.

Faul, F., Erdfelder, E., Lang, A.G., et al. (2007) G*Power 3: A Flexible Statistical Power Analysis Program for the Social, Behavioral, and Biomedical Sciences. Behavior Research Methods, 39, 175-191.

Gelderen, M. V. (2010). Autonomy as the guiding aim of entrepreneurship education. Education + Training, 52(8/9), 710-721.

GEM BRASIL, GEM. Global Entrepreneurship Monitor. (2010), (2012) e (2015). Empreendedorismo no Brasil: Relatório Técnico. São Paulo.

Gagné, M., \& Deci, E. L. (2005, January). Self-determination theory and work motivation. Journal of Organizational Behavior, Malden, 26, 331-362.

Gibb, A. (2002). In pursuit of a new 'enterprise' and 'entrepreneurship' paradigm for learning, creative destruction, new values, new ways of doing things and new combinations of knowledge. International Journal of Management Reviews, 4(3), 213-31.

Hair, J. F., Hult, T. M., Ringle, C. M., \& Sarstedt, M. (2014). A Primer on Partial Least Squares Structural Equation Modeling (PLS-SEM). Los Angeles: SAGE.

Hytti, U., Stenholm, P., Heinonen, J., \& Seikkula-Leino, J. (2010). Perceived learning outcomes in entrepreneurship education: The impact of student motivation and team behaviour. Education + Training, 52(8/9), 587-606.

Jesuíno, J.C., Reis, e., \& Cruz, E. (1988). Motivações empresariais em Portugal, uma perspectiva trasncultural. Revista de Gestão, 2/3.43-50.

Joensuu-Salo, S., Varamäki, E., \& Viljamaa, A. (2015). Beyond intentions - what makes a student start a firm? Education + Training, 57(8/9), 853-873.

Kanfer, R., \& Heggestad, E. D. (1997). Motivational traits and skills: A person-centered approach to work motivation. Research in Organizational Behavior, 19, 1-56.

Kuratko, D. F., Hornsby, J. S,\& Naffziger, D. W. An Examination of Owner's Goals in Sustaining Entrepreneurship. Journal of Small Business Management, 33(1), 24-33, 1997. 
avieri, C. Educação...empreendedora? In: Lopes, R.M. A. (Orga.) (2010). Educação empreendedora: conceitos, modelos e práticas. cap. 1. Rio de Janeiro: Elsevier; São Paulo: Sebrae.

Lepper, M. R., Henderlong, J. \& Iyengar, S. S. (2005). Intrinsic and extrinsic motivational orientations in the classroom: age differences and academic correlates. Journal of Educational Psychology, 97(2), 184-196.

Lim, S. Y., \& Chapman, E. (2015). Adapting the academic motivation scale for use in pre-tertiary mathematics classrooms. Mathematical Educational Research Journal, 27, 331-357.

Maslow, A. H. (1943). A theory of human motivation. Psychological Review, 50, 390-396.

Matlay, H. (2008). The impact of entrepreneurship education on entrepreneurial outcomes, Journal of Small Business and Enterprise Development, 15(2), 382-396.

Mcclelland, D., \& Burnham, D. H. (1995). Power is the great motivator. Harvard: Harvard Business School Press.

McClelland, D. C., Atkinson, J. W., Clark, R. A. \& Lowell, E. L. (1953). The Achievement Motive. New York: Appleton-Century-Crofts.

Morris, M. H., Shirokova, G., \& Tsukanova, T. (2017). Student entrepreneurship and the university ecosystem: a multi-country empirical exploration. European J. International Management, 11(1), 65-85.

Morris, M. H., Webb, J. W., Fu, J., \&Singhal, S. (2013) A competency-based perspective on entrepreneurship education: conceptual and empirical insights. Journal of Small Business, 51(3), 352- 369.

Morris, N. M., Kuratko, D. F., \& Pryor, C.G. (2014) Building blocks for the development of university-wide entrepreneurship. Entrepreneurship Research Journal, 4(1), 45-68.

Nassif, M. J., Ghobril, A. N., \& Silva (2010). (S. Understanding the Entrepreneurial Process: A Dynamic Approach. BAR - Brazilian Administration Review, 7(2), 213-226.

Neck, H., Greene, P, \& Brush, C. (2014). Practice-based entrepreneurship education using actionable theory'. In M. H. Morris(Ed.).Annals of Entrepreneurship Education and Pedagogy. Cheltenham: Edward Elgar Publishing, 3-20.

Niemiec, C. P., \& Ryan, R. M. (2009). Autonomy, competence, and relatedness in the classroom: Applying self-determination theory to educational practice. Theory and Research in Education, 7, 133-144.

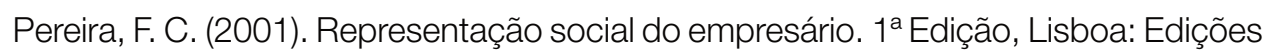
Silabo, Lda.

Preedy, S., \& Jones, P. (2015). An investigation into university extra-curricular enterprise support provision, Education + Training, 57(8/9), 992-1008.

Rindova, V., Barry, D., \&Ketchen, D. J., JR. (2009). Entrepreneuring as emancipation. Academy of Management Review, 34, 477-491.

Ringle, C.; Silva, D.; Bido, D. S. (2014) Modelagem de Equações Estruturais com utilização do Smartpls.Revista Brasileira de Marketing, v.13, n2, p. 54-71.

Robichaud, Y., Mcgraw, E., \& Roger, A. (2001). Toward de Development of a Measuring Instrument for Entrepreneurial Motivation. Journal of Developmental Entrepreneurship, 6(2), 189-201. 
Rocha, E. L. C., \& Freitas, A. A. F. (2014) Avaliação do Ensino de Empreendedorismo entre Estudantes Universitários por meio do Perfil Empreendedor. RAC, 18(4), 465-486.

Savelsbergh, C. M. J. H., Van Der Heijden, B. I. J. M., \&Poell, R. F. (2009). The development and empirical validation of a muldimensional measurement instrument for Team Learning Behaviors. Small Group Research, 40(5), 578-607.

Scacchetti, F. A. P., Oliveira, K. L., \& Rufini, S. E. (2014). Medida de motivação para aprendizagem no Ensino Técnico Profissional. Avaliação Psicológica, 13(2), 297-305.

Scheinberg, S., \& MacMillan, I. C. (1988). An 11-country study of motivations to start a business. In Frontiers of Entrepreneurship Research, Babson College, Proceedings of the 8th Annual Babson College Entrepreneurship Research Conference (pp. 669-687). Massachusetts

Sivapalan, A., \& Balasundaram, N. (2012). Level of entrepreneurial intention of the management undergraduates in the University of Jaffna, Sri Lanka: scholars and undergraduates perspective. South Asian Academic Research Journals, 2(10), 24-42.

Sivarajah, K., \& Achchuthan, S. (2013). Entrepreneurial Intention among Undergraduates: Review of Literature. European Journal of Business and Management, 5(5), 98-124.

Stover, J. B., Iglesia, G. L., Boubeta, A. R., \& Liporace, M. F. (2012). Academic motivation scale: adaptation and psycometric analyses for high school and college students. Psychology Research and Behavior Management, 2(5), 71-83.

Sobral, D. T. (2003) Motivação do aprendiz de medicina: uso da escala de motivação acadêmica. Psicologia: Teoria e Pesquisa, 19(1), 25-31.

Townsend, D. M., Busenitz, L. W., \& Arthurs, J. D. (2010). To start or not to start: outcome and ability expectations in the Decision to start a new venture. Journal of Business Venturing, 25(2), 192-202.

Vale, G. M. V., Correa, S., \& Reis, R. F. (2014, junho). Motivações para o empreendedorismo: necessidade versus oportunidade? Revista de Administração Contemporânea, Curitiba, 18(3), 311-327.

Vallerand, R. J., Blais, M. R., Briere, M., \& Pelletier, P. (1989). Construction and validation of the echelle de motivation en Education (EME). Canadian Journal of Behavioral Sciences, 3(21), 323-349.

Vallerand, R. J., Pelletier, L. G., Blais, M. R., Briere, M., Senecal, C., \& Vallieres, E. F. (1992). The academic motivation scale: a measure of intrinsic, extrinsic, and amotivation in education. Educational and Psychological Measurement, 52(4), 1003-1017.

Vallerand, R. J., Pelletier, L. G., Blais, M. R., Briere, M.,Senecal, C., \& Vallieres, E. F. (1993). On the assessment of intrinsec, extrinsec, and a motivation in Education: Evidence on the concurrent and construct validity of the academic motivation scale. Educational and Psychological Measurement, 53, 159-172.

Veciana, J. M. (1999). Creación de empresas como programa de investigación científica. Revista Europea de Dirección y Economía de la Empresa, 8(3), 11-36.

Wang, Y., Lin, S., Yeh, C., Li, C., \& Li, H. (2016). What drives students' cyber entrepreneurial intention: The moderating role of disciplinary difference. Thinking Skills and Creativity, (22), 22-35. 
Wilkesmann, U., Fischer., H, Virgillito, A. (2012). Academic motivation of students: the German case. Dortmund: Technische Universität Dortmund;. 02, 01-20.

Zhang, B., Li, Y., M., Li, J., Li, Y., \& Zhang, H. (2016). The revision and validation of the academic motivation scale in china. Journal of Psychoeducational Assessment, 34(1), 15-27.

\section{Apêndice A - Itens utilizados no estudo.}

\section{A1. Escala de motivação acadêmica (Likert de 10 pontos).}

Usando a escala de 01 a 10, indique uma nota (números inteiros) para cada um dos itens correspondes, atualmente, a uma das razões porque você vem à Universidade:

1. Porque preciso do diploma, ao menos, a fim de conseguir uma ocupação bem remunerada, no futuro.

2. Porque sinto satisfação e prazer enquanto aprendo coisas novas.

3. Porque acho que a formação universitária ajuda a me preparar melhor para a carreira que escolhi.

4. Porque gosto muito de vir à universidade.

5. Honestamente, não sei; acho que estou perdendo meu tempo.

6. Pelo prazer que sinto quando supero a mim mesmo nos estudos.

7. Para provar a mim mesmo que sou capaz de completar o curso.

8. A fim de obter um emprego de prestígio, no futuro.

9. Pelo prazer que sinto quando descubro coisas novas que nunca tinha visto ou conhecido antes.

10. Porque o curso me capacitará, no final, a entrar no mercado de trabalho de uma área que eu gosto.

11. Porque, para mim, a universidade é um prazer.

12. Já tive boas razões para isso; agora, entretanto, eu me pergunto se devo continuar.

13. Pelo prazer que sinto quando supero a mim mesmo em alguma de minhas realizações pessoais.

14. Por causa do fato que me sinto importante quando sou bem-sucedido na universidade.

15. Porque quero levar uma boa vida no futuro.

16. Pelo prazer que tenho em ampliar meu conhecimento sobre assuntos que me atraem.

17. Porque isso me ajudará a escolher melhor minha orientação profissional.

18. Pelo prazer que tenho quando me envolvo em debates com professores interessantes.

19. Não atino (percebo) porque venho à universidade e, francamente, não me preocupo com isso. 
20. Pela satisfação que sinto quando estou no processo de realização de atividades acadêmicas difíceis.

21. Para mostrar a mim mesmo que sou uma pessoa inteligente.

22. A fim de ter uma boa remuneração no futuro.

23. Porque meus estudos permitem que continue a aprender sobre muitas coisas que me interessam.

24. Porque eu creio que a formação universitária aumentará minha competência como profissional.

25. Pela euforia que sinto quando leio sobre vários assuntos interessantes.

26. Não sei; não entendo o que estou fazendo na universidade.

27. Porque a universidade me permite sentir uma satisfação pessoal na minha busca por excelência na formação.

28. Porque quero mostrar a mim mesmo que posso ter sucesso nos meus estudos.

A2. Escala de motivação empreendedora (Likert de 10 pontos).

Eu criaria a minha própria empresa para:

1. Pôr em prática as minhas próprias ideias.

2. Ter mais autonomia no trabalho.

3. Ter uma maior flexibilidade na vida privada.

4. Tirar vantagens das novas tecnologias.

5. Implementar um negócio de sucesso.

6. Implementar um negócio inovador.

7. Realização pessoal.

8. Ter mais rendimentos.

9. Ser rico.

10. Fugir do desemprego.

11. Ter mais segurança no futuro.

12. Se beneficiar de subsídios para a criação de uma empresa.

13. Ganhar prestígio na sociedade.

14. Realizar algo e ser reconhecido por isso.

15. Ter mais influência na sociedade.

16. Ser mais respeitado pelos meus amigos e colegas.

17. Seguir o exemplo de empresários que admiro.

18. Dar continuidade à tradição empresarial da minha família. 